\title{
Bulbus psododivertikülde mide çıkış obstrüksiyonuna neden olan ve gastroskopi ile mideye alınması sonrası ileus gelişen bezoar: olgu sunumu ve literatürün gözden geçirilmesi (duodenal bezoar)
}

Bezoar which grown in bulb pseudodiverticulum causing gastric outlet obstruction and causing ileus after removed to in the stomachc by gastroscopy: a case report and literature review (duodenal bezoar)

Ahmet UYANIKOĞLU ${ }^{1}$, Haşim NAR ${ }^{1}$, Yusuf YÜCEL ${ }^{2}$, Ahmet ŞEKER ${ }^{2}$, Ferzan AYDIN ${ }^{1}$, Necati YENICE

Harran Üniversitesi Tip Fakültesi, ${ }^{1}$ Gastroenteroloji Bilim Dall, ${ }^{2}$ Genel Cerrahi Ana Bilim Dall, Şanlıurfa

Bezoar, yabancı cisim veya gıdaların beslenme yolunda oluşturduğu kitlelerdir. Mide operasyonu geçirmiş olanlarda bezoar sıklığı artmaktadır. Ince barsakta bezoar az görülür ve nadiren ileusa neden olabilir. Bu yazıda, duodenuma yerleşmiş bezoarı olan, gastrik ameliyat geçirmiş, 55 yaşında kadın hasta sunulmuştur. Hastada bezoarın mideye alınmasını takiben ileus gelişmiş ve laparotomi yapılmıştır. Hasta ameliyattan bir hafta sonra şifa ile taburcu edilmiştir

Anahtar kelimeler: Bezoar, mide çıkış yolu obstrüksiyonu, ileus
The incidience of gastric surgery for bezoars, foreign material that amass in the stomach, is increasing. Bezoars in the small intestine are less common and can, in rare cases, cause ileus. In this article, a 55 year old female patient treated by gastric surgery for bezoars located in the duodenum is presented. Following receipt of bezoars in the patient, a gastric ileus and laparotomy was performed. One week after surgery the patient was discharged, healing well.

Key words: Bezoar, gastric outlet syndrome, ileus

batın dahil olmak üzere nonspesifik gastrointestinal şikayetler bulunabilir (7).

Fitobezoar en yaygin bezoar türü olup, sebze ve meyvelerin sindirilmeyen derivelerinden oluşur (8). Fitobezoar ince barsak obstrüksiyonunun alışılmamış bir nedenidir. Ince barsak mekanik obstrüksiyonlarının \%0.4-4'ünü oluşturur. Tedavisi cerrahidir (9).

$\mathrm{Bu}$ yazıda bulantı-kusma ile prezente olup, mide çııış yolu obstrüksiyonuna neden olmuş, bulbusta psododivertikül cebine yerleşmiş bezoarı olan, gastroskopi ile mideye alındıktan sonra ileus gelişen, 55 yaşında kadın hasta sunulmuştur.

\section{OLGU SUNUMU}

Yaklaşık 20 yıl önce mide ameliyatı öyküsü olan, bulantıkusma şikayeti nedeniyle interne edilen hastanın fizik muayenesinde, batın distandü olup, organomegali saptanmadı. Rutin hemogram ve biyokimya tetkiklerinde özellik yoktu. Ilk gastroskopisinde midede aşırı miktarda safra ve sıvı gıda saptanan hastanın oral alımı kapatılarak, nazogastrik sonda takıldı ve 1 gün sonra gastroskopisi tekrarlandı. Mide lümeninde halen fazla miktarda safra sekresyonu vardı. Pilordan geçildiğinde lümeni tıkayan, 4-5 cm çapında dev kitle gö- 


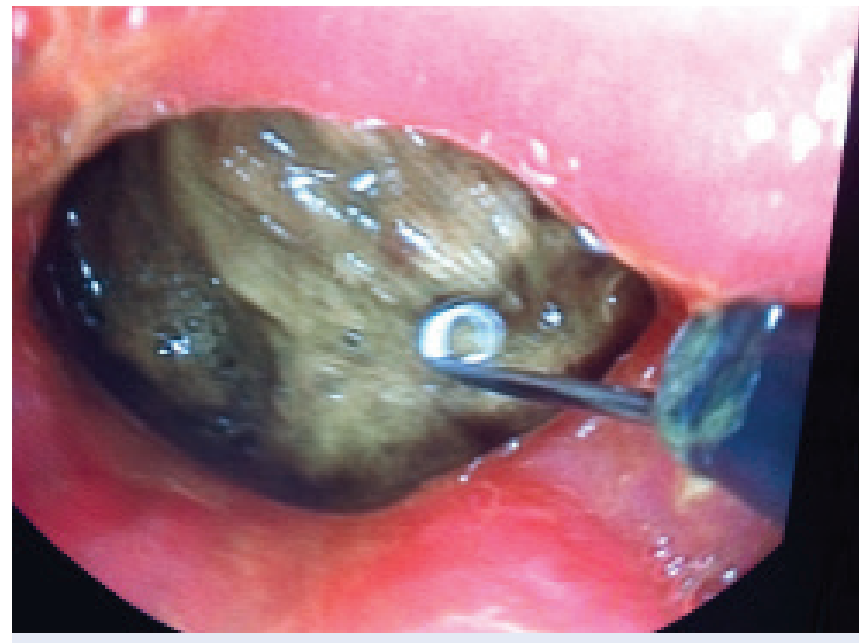

Resim 1. Duodenumda tıkaç yapmış bezoar.

rüldü (Resim 1). Kenarından manevrayla ikinci kısma geçilebildi. Korpus küçük kurvaturda ikinci bir lümen görüldü, hastaya simple gastro-jejunostomi ameliyatı yapıldığı anlaşıdı. Mide içeriği aspire edilerek bulbustaki dev cisim tripot, biyopsi pensi, yabancı cisim pensi ile çıkarılmaya çalışıldı. Cismin parçalandığı ve kanama olmadığı görüldü, bunun bezoar olabileceği düşünüldü. Yaklaşık 1 saatlik müdahaleye rağmen bezoarın ancak bir kısmı çıkarılabildi. Hastaya parenteral sıvı yanında 12 saatte 3 litre kola içirildi. Issleme 2.gün devam edildi ve cismin tamamı mideye, bir kısmı dışarıya çıkarıldı (Resim 2,3). Işlem sonrası karın ağrısı artarak devam eden, bulantı-kusma şikayeti gerilemeyen hastada düz batın grafisinde hava-sıvı seviyeleri saptandı. Hastada ileus düşünülerek genel cerrahi tarafından laparatomi yapıldı. Jejunumda bezoar parçaları saptanarak çekuma itildi. Hasta ameliyattan 1 hafta sonra şifa ile taburcu edildi.

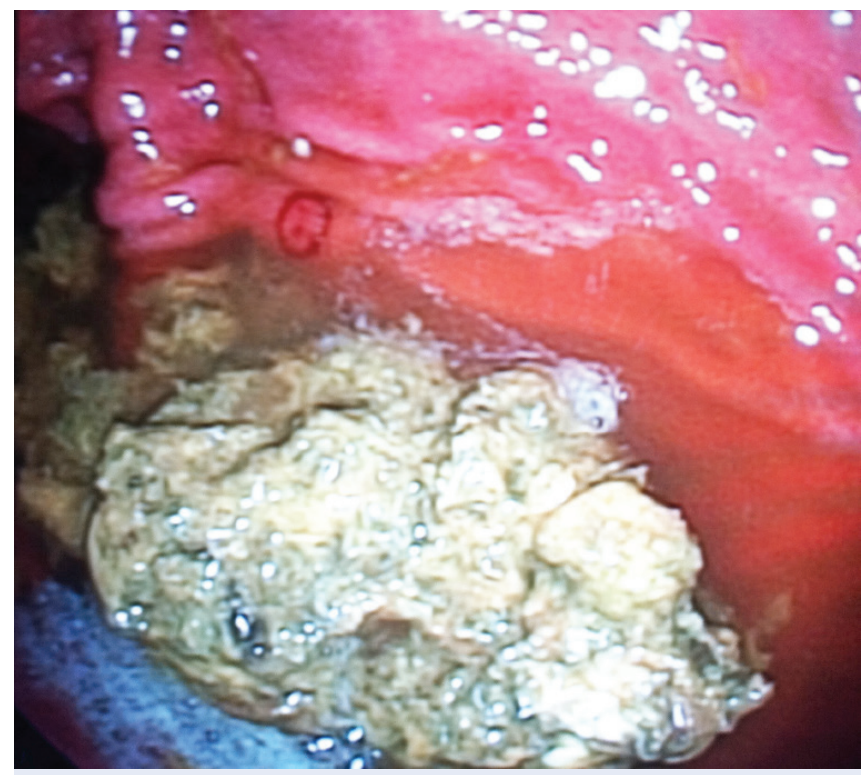

Resim 2. Bezoarın mideye alınması

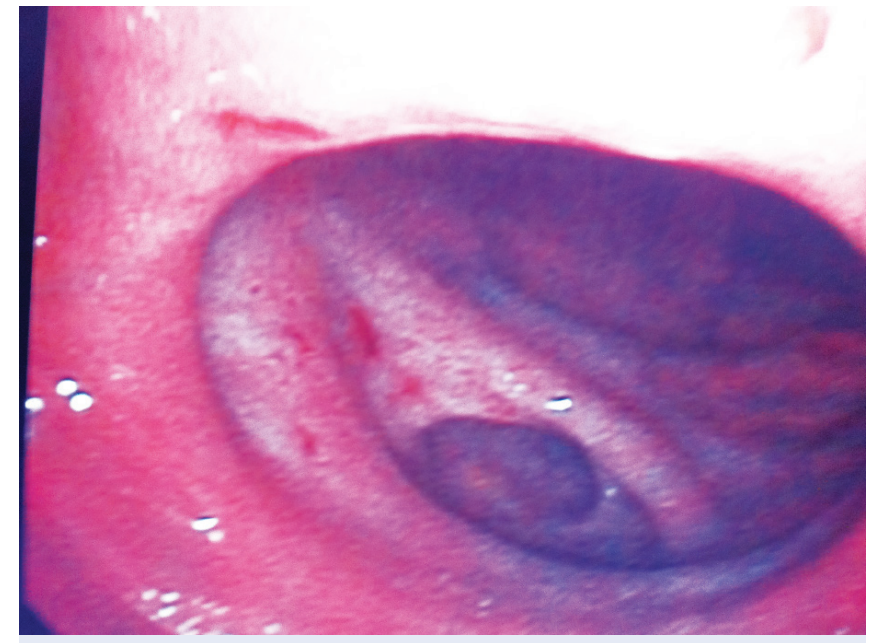

Resim 3. Bezoar çıkarıldıktan sonra duodenumun görünümü.

\section{TARTIŞMA}

Bezoarlar yutulan yabancı materyallerin gastrointestinal traktusta birikmesiyle meydana gelir ve materyalin içeriğine göre fitobezoar (hortobezoar), trikobezoar (pilobezoar, hairball), midede taşlaşmış cisimler veya ilaç bezoarı olabilir. Fitobezoarlar çok yaygındırlar ve portakal, hurma gibi iyi sindirelemeyen meyve çekirdekleri buna neden olabilir. Özellikle geçirilmiş ameliyat sebebiyle asit sekresyonu ve motilitesi azalmış bir midede, bu vizköz materyal, bezoar oluşması için bir nukleus oluşturabilir. Dişsiz veya bozuk diş yapısına bağlı oral hazım ve çiğnemenin yetersiz oluşu, geçirilmiş mide ameliyatı sonucu, mide asiditesinin azalması ve mide boşalmasının yavaşlaması da bir faktördür. Çeşitli serilerde \%55,6 ve $\% 70$ gibi yüksek oranda geçirilmiş mide ameliyatı oranlanı verenler vardır. Midede bezoar oluşmasına sebep olan diğer bir faktör olarak diabetik nöropatiye bağll "gastroparesis diabeticorum" gösterilmiştir. Diabetik nöropatinin, uygulanmış vagotomi ile birlikte mide motilitesini azalttığı, solid gıdaların mideden boşalmasının geciktiği ileri sürülmüştür Bezoar siklıkla psikriyatrik problemleri olan veya gastrik cerrahi geçirmiş hastalarda midede, yabancı cisimlerin yenilmesi ile oluşan kitlelerdir (1, 7, 10-13). Bizim hastamızda geçirilmiş mide ameliyatının muhtemel predispozisyon yaratan neden olduğu, cismin yapısından dolayı muhtemelen fitobezoar olduğu düşünüldü.

Trikobezoar, mental gerilik gösteren çocuklar ve psikiyatrik hastalarda görülür. Bu hastalar paranoid, obsesif, hatta Down sendromlu olabilirler. Trikobezoarların özel bir tipi Rapunzel sendromudur. Bu olgularda midedeki saç kitlesinden başka bu kitleden başlayarak tüm ince bağırsağı geçerek sağ kolona kadar uzanan saç yumakları mevcuttur (1). Hastamızda mental gerilik veya down sendromu yoktu ve cismin makroskopik görünümü, parçalanıyor olması trikobezoar değil, fitobezoar olduğunu düşündürdü. 
Fitobezoar olgularında başlıca şikayetler epigastriumda müphem sıkıntı, bazen 20 kilograma varan kilo kaybı, epigastriumda şişkinlik bulantı ve kusma üst gastrointestinal kanama, disfajidir. Pilorik obstrüksiyon yapanlar olduğu gibi, safra yolu obstrüksiyonu ve afferent loop sendromu meydana getirenler, intestinal obstrüksiyon ve perforasyon yapanlarda olmuştur. Trikobezoarlarda başlıca şikayetler ağrı, iştahsızlık, kilo kaybı, kusma, sarılık, anemi, hipoalbüminemidir. Pankreatit, intestinal perforasyon, intestinal tıkanıklık, intussusseption gibi komplikasyonlara yol açabilir $(1,12,13)$. Hastamız bulantı-kusma şikayeti ile prezente olmuştu, belirgin kilo kaybı yoktu. Klinik ve laboratuvar olarak safra yollarına bası veya pankreatit bulgusu yoktu. Gastroskopik müdahale sonrası da ileus tablosu gelişti.

Mide fitobezoarları ekseriyetle, konservatif yöntemlerle tedavi edilebilir. Tekrarlayan dozlarla uygulanan cellulase, mide fitobezoarlarının eritilmesinde en etkili proteolitik enzimdir (14). Papain ve acetyleystein gibi diğer proteolitik enzimlerin cellulase kadar etkili olmadığı bildirilmiştir. Endoskopi, bezoarların hem teşhis, hem tedavisinde kullanılmıştır. Büyük alan fitobezoarların kırılarak, parçalanması ve parçaların ayrı ayrı çıkarılması gerekebilir. Bazen, 3-4 seansta tam temizlik yapılabilir. Endoskopik tedavinin bir ileri şekli olarak "Electrohydraulic Lithotripsy" kullanılması ve endoskopik fragmantasyon ile cellulase/cystein/metachopramide üçlüsü ile kombine tedaviden başarılı sonuçlar alındığını ifade eden çalışmalar vardır (1). Hastamızda bezoar midede değildi, duodenum psododivertikülde idi. Gastroskopi ile 3 seansta parçalanarak mideye alındı.

Periampüller duodenal divertiküler bezoar oldukça nadirdir. Klinik bulgu spektrumu lokalizasyona bağlı olarak semptomsuz hastadan, akut batına kadar değişmektedir. Biliyer obstrüksiyona neden olan bezoar olgusu nadiren bildirilmiştir, tedavi cerrahidir. Literatürde akut pankreatit ile prezente olan, ardından periampüller divertikülden duodenum lümenine migre olurken, obstrüksiyona neden olan, bilgisayarlı tomografi (BT)'de pankreatik abse ve mikroperforasyon görünümü benzeri bulgular saptanan hasta sunulmuştur. Hastadan cerrahi olarak bezoar uzaklaştırılmış ve tam iyileşme sağlanmıştır (15). Bizim olgumuzun bildirilen bu hastaya benzeyen yönleri duodenum divertikülünde oluşmuş olması, duodenum lümenine migre olarak ileusa neden olması ve cerrahi olarak uzaklaştırılması idi. Farklı tarafları ise periampüller değil, bulbus ön yüz divertikülüne yerleşmiş olması ve akut pankreatite neden olmaması idi.

Otuzdokuz hastadan cerrahi olarak 56 bezoarın çıkarıldığı çalışmada, bezoar en sık jejunumda ( $n=26 / 56, \% 46.4$ ) saptanmıştır. 16 hastada (\%41) gastrointestinal traktta multipl bezoar lokasyonu saptanmıştır (16). Bezoar nedeniyle ince barsak obstrüksiyonu sık değildir. Geçirilmiş gastrik rezeksiyon, gastrojejunostomi veya piloroplasti bezoar oluşumuna predispozisyon yaratır. Normal midede ve primer ince barsak bezoarı oldukça nadirdir. Ince barsakta bezoar sadece divertikül, striktür veya tümörü olan hastalarda görülür (8). Diyabetik yaşlı hasta yemek sonrası başlayan 5 günlük karın ağrısı, komplike ince barsak obstrüksiyon belirtileri ile müracaat etmiş, hastada geçirilmiş, 14 yll önce duodenal ülser nedeniyle yapilan, Billroth II hemigastrektomi, trunkal vagotomi öyküsü saptanmış. Başka bir olgu sunumunda 57 yaşında erkek hasta ince barsak obstrüksiyonu semptom ve bulguları ile prezente olmuş, eksploratuvar laparotomide ileumda obstrüksiyon nedeni ile fitobezoar saptanmış, histopatoloji ile konfirme edilmiştir $(8,9,15)$. Bizim hastamız 55 yaşında kadın hasta idi, 20 yll önce operasyon öyküsü vardı, ancak ne için ve ne ameliyatı yapıldığı bilinmiyordu. Duodenum psödodivertikülünde bezoar saptandı, ikinci kısma manevrayla geçilebiliyordu, ameliyatın duodenal ülser nedeni ile yapılmış olabileceği düşünüldü. Gastroskopisinden ameliyatın simple gastro-jejunostomi ameliyatı olduğu anlaşıldı. Yabancı cisim histopatolojik olarak konfirme edilmemekle beraber makroskopik görünümü ve parçalanabilir olması nedeniyle muhtemelen fitobezoardi.

Bezoarlar yabancı cisim olup, gastrointestinal sistemde epigastrik rahatsızlı, erken doyma, konstipasyon ve nadiren gastrointestinal obstrüksiyon gibi nonspesifik semptomlara neden olur. Literatürde migre olarak sekonder gastrointestinal sistem obstrüksiyonuna neden olan bezoar bildirilmiştir. Endoskopik manipülasyon ve Coca-Cola gibi kimyasal solüsyonlar gastrik bezoarları parçalayarak, fragmente parçaların ince barsakta ileusa neden olabileceği bildirilmiştir. Bu durumda abdominal X-ray ve BT zamanında tanı için önemli rol oynar (17). Klinik olarak ince barsak obstrüksiyonuna neden olan bezoar tanısını preoperatif olarak koymak zordur. BT ile erken tanı koymak ve komplikasyon riskini azaltmak mümkündür $(13,18,19)$. Bizim hastamızın ilginç yönü endoskopik manipülasyonla duodenum divertikülden mideye alındıktan ve Coca-Cola verildikten 1-2 gün sonra jejunuma migre olması ve ileus tablosuna yol açması idi. Tanıda batın grafisinde hava-sıvı seviyelerine rastlanması ileusu düşündürmüş ve hasta ameliyat edilmiştir.

Gastrik bezoarlar rekürren ince barsak obstrüksiyonu ayırıcl tanısında düşünülmelidir (20). Bezoar Roux-en-Y gastrik bypass sonrası ince barsak obstrüksiyonunun nadir bir nedenidir. 34 yaşında erkek hasta morbid obezite nedeniyle Rouxen-Y ameliyatından 5.5 yll sonra fitobezoara sekonder jejunojejunal anastomozda ince barsak obstrüksiyonu ile prezente olmuş, hastanın anamnezinde rekürren karın ağrısı varmış (21). Fitobezoarlar daha önce gastrik cerrahi geçiren hastalarda, kötü çiğneme fonksiyonu olan hastalarda veya fazla fiber tüketiminde akut ince barsak tıkanıklığı geliştiğinde ayırıcı tanıda akla gelmelidir. Abdominal BT tanı ve acil cerrahi kararı almada kullanışlıdır. Mümkün olursa fitobezoar parça- 
lanmalı, çekuma itilmelidir. Laparoskopik fregmantasyonun bu gibi hastalarda kullanışlı olabileceği bildirilmiştir (22). Bizim hastamızda rekürren karın ağrısı yoktu. Cerrahi kararı klinik ve düz batın grafisi ile konuldu, laparatomi yapıldı ve jejunumdaki parçalar çekuma atıldı.

Sonuç olarak bezoar geçirilmiş mide ameliyatı olan hastalar-

\section{KAYNAKLAR}

1. Ersan Y, Yavuz N, Yüceyar S, et al. Gastric bezoars requiring surgical treatment. Cerrahpaşa J Med 2005;36:128-33.

2. Tatar C, Karşıdağ T, Özgül H, Tüzün S. Gastrik Trikobezoar: Olgu Sunumu, Haseki Tıp Bülteni 2013;51:141-3.

3. Visvanathan R. Cement bezoars of the stomach. Br JSurg 1986;73:381-2.

4. Kaneko H, Tomomasa T, Kubata Y, et al. Pharmacobezoar complicating treatment with sodium alginate. J Gastroenterol 2004;39:69-71.

5. Chisholm EM, Leong HT, Chung SC, Li AK. Phytobezoar: an uncommon cause of small bowel obstruction. Ann R Coll Surg Engl 1992;74:342-4.

6. Bölükbaş FF, Bölükbaş C, Akbayır N, et al. Endoskopik olarak saptanan bezoarların klinik önemi. Türkiye Klinikleri J Gastroenterohepatol 2003;14:151-4

7. Emirpolat G, Uğur T, Bülbüloğlu E. Nadir bir ileus nedeni: bezoar. Ege Tip Dergisi 2009;48:217-20.

8. de Toledo AP, Rodrigues FH, Rodrigues MR, et al. Diospyrobezoar as a cause of small bowel obstruction. Case Rep Gastroenterol 2012;6:596-603.

9. Pujar KA, Pai AS, Hiremath VB. Phytobezoar: a rare cause of small bowel obstruction. J Clin Diagn Res 2013;7:2298-9.

10. Vitellas KM, Vaswani K, Bennett WF. Case 2. Small-bowel bezoar. AJR Am J Roentgenol. 2000;175:873;876-8

11. Ripollés T, García-Aguayo J, Martínez MJ, Gil P. Gastrointestinal bezoars: Sonographic and CT characteristics AJR Am J Roentgenol 2001;177:65-9.

12. Shah D, Desai AB. Isolated ileal bezoar causing small bowel obstruction BMJ Case Rep 2012;2012. pii: bcr0120125656.

13. Salemis NS, Panagiotopoulos N, Sdoukos N, Niakas E. Acute surgical abdomen due to phytobezoar-induced ileal obstruction. J Emerg Med 2013;44:e21-3. Epub 2011 Oct 29. da, inatçı bulantı-kusma şikayetinde akla gelmelidir. Duodenum nadir bir lokalizasyonu olmasına rağmen hastamızda olduğu gibi psödodivertiküle yerleşerek mide çıkış obstrüksiyonuna neden olabilir. Gastroskopi tanı ve tedavi için esastır. Ancak tam olarak dışarı alınamazsa yine hastamızda olduğu gibi migre olarak ince barsak obstrüksiyonu-ileusa neden olabilir, bu durumda tedavi cerrahidir.
14. Bonilla F, Mirete J, Cuesta A, et al. Treatment of gastric phytobezoars with cellulase. Rev Esp Enferm Dia 1999;91:809-14.

15. Kim JH, Chang JH, Nam SM, et al. Duodenal obstruction following acute pancreatitis caused by a large duodenal diverticular bezoar. World J Gastroenterol 2012;18:5485-8.

16. Altintoprak F, Degirmenci B, Dikicier E, et al. CT findings of patients with small bowel obstruction due to bezoar: a descriptive study. ScientificWorldJournal 2013;2013:298392.

17. Chen HW, Chu HC. Migration of gastric bezoars leading to secondary ileus. Intern Med 2011;50:1993-5.

18. Hsu SN, Huang TY, Hsieh TY. Unusual abdominal pain and vomiting. Gastroenterology 2012;143:e3-4.

19. Oh SH, Namgung H, Park MH, Park DG. Bezoar-induced small bowel obstruction. J Korean Soc Coloproctol 2012;28:89-93.

20. Coufal NG, Kansagra AP, Doucet J, et al. Gastric trichobezoar causing intermittent small bowel obstruction: report of a case and review of the literature. Case Rep Med 2011;2011:217570.

21. Roy M, Fendrich I, Li J, et al. Treatment option in patient presenting with small bowel obstruction from phytobezoar at the jejunojejunal anastomosis after Roux-en-Y gastric bypass. Surg Laparosc Endosc Percutan Tech 2012;22:e243-5.

22. Dirican A, Unal B, Tatli F, et al. Surgical treatment of phytobezoars causes acute small intestinal obstruction. Bratisl Lek Listy 2009;110:158-61. 